\title{
Os impactos da pandemia do COVID-19 no setor de serviços brasileiro
}

\author{
The impacts of the COVID-19 pandemic on the Brazilian service sector \\ Los impactos de la pandemia del COVID-19 en el sector de servicios brasileño
}

Fábio da Silva ORCID: https://orcid.org/0000-0003-0039-0128 Universidade Potiguar, Brasil E-mail: fabiosoyme@hotmail.com César Ricardo Maia de Vasconcelos ORCID: https://orcid.org/0000-0003-0398-5733 Universidade Potiguar, Brasil

E-mail: cesarmvasconcelos@gmail.com

Cristine Hermann Nodari

ORCID: https://orcid.org/0000-0003-0397-337X Universidade Potiguar, Brasil

E-mail: cristine.nodori@gmail.com

Tarciara Magley da Fonseca Pereira ORCID: https://orcid.org/0000-0002-7570-8471 Universidade Potiguar, Brasil E-mail: tarciara@ufersa.edu.br

Laís Karla da Silva Barreto

ORCID: https://orcid.org/0000-0002-5267-5355 Universidade Potiguar, Brasil E-mail: laisbarreto@gmail.com

Anderson Lopes Nascimento

ORCID: https://orcid.org/0000-0003-2538-9000 Universidade Federal do Piaú, Brasil

E-mail: adm.anderson@ hotmail.com

Sérgio Castro Gomes

ORCID: https://orcid.org/0000-0002-1731-8766 Universidade Federal de Viçosa, Brasil E-mail: sergio.gomes@unama.br

Carlos Dias Chaym

ORCID: https://orcid.org/0000-0002-8685-4650 Faculdade Cearense, Brasil E-mail: carlosdiaschaym@gmail.com

Juliana Bianca Maia Franco

ORCID: https://orcid.org/0000-0002-7566-2688 Universidade Potiguar, Brasil E-mail: juliana_franco_@hotmail.com

Arly Dayany Fernandes de Carvalho ORCID: https://orcid.org/0000-0001-7758-7901 Universidade Estadual do Rio Grande do Norte, Brasil E-mail: arly.carvalho@ufersa.edu.br

Wilton Teixeira Celestino

ORCID: https://orcid.org/0000-0002-7147-8621 Universidade Estadual do Rio Grande do Norte, Brasil E-mail: wilton@hotmail.com

\begin{abstract}
Resumo
O setor de serviços foi responsável por 74\% do Produto Interno Bruto no Brasil em 2019. Dada a relevância do setor nos últimos anos, o presente estudo tem como objetivo analisar os impactos provocados pela pandemia do novo coronavírus no setor de serviços no país. A metodologia utilizada baseia-se nas Pesquisas Anuais do Comércio, da Indústria e de Serviços, bem como da Pesquisa Mensal de Serviços de maio de 2020 divulgadas pelo Serviço Brasileiro de Apoio às Micro e Pequenas Empresas (SEBRAE). Os resultados mostram que o setor de serviços foi o que mais cresceu em números de empresas e geração empregos nos últimos anos. Nos primeiros cinco meses do ano houve retração do volume e receita em todas as cinco classificações de serviços utilizadas na análise dos dados. A queda mais acentuada foi nas atividades relacionadas ao turismo.
\end{abstract}

Palavras-chave: Setor de serviços; COVID-19; Crise sanitária e econômica; SEBRAE. 


\begin{abstract}
The service sector is responsible for $74 \%$ of the Gross Domestic Product in Brazil. Given the relevance of the sector in recent years, the present study aims to analyze the impacts caused by the pandemic of the new coronavirus on the services sector in the country. The methodology used is based on the Annual Survey of Commerce, Industry and Services, as well as the Monthly Survey of Services of May 2020 released by Brazilian Micro and Small Business Support Service (SEBRAE). The results show that the service sector was the one that most grew in numbers of companies and job creation in the last years. In the first five months of the year, volume and revenue declined in all five service classifications used in the data analysis. The sharpest drop was in tourism-related activities.
\end{abstract}

Keywords: Service sector; COVID-19; Sanitary and economic crisis; SEBRAE.

\title{
Resumen
}

El sector servicios fue responsable del 74\% del Producto Interno Bruto de Brasil en 2019. Dada la relevancia del sector en los últimos años, este estudio tiene como objetivo analizar los impactos causados por la nueva pandemia de coronavirus en el sector servicios en el país. La metodología utilizada se basa en las Encuestas Anuales de Comercio, Industria y Servicios, así como la Encuesta Mensual de Servicios de mayo de 2020, publicada por el Servicio Brasileño de Apoyo a la Micro y Pequeña Empresa (SEBRAE). Los resultados muestran que el sector servicios fue el que más creció en número de empresas y creación de empleo en los últimos años. En los primeros cinco meses del año, hubo una retracción en el volumen y los ingresos en las cinco clasificaciones de servicios utilizados en el análisis de datos. La caída más pronunciada se registró en las actividades relacionadas con el turismo.

Palabras clave: Sector de servicios; COVID-19; Crisis sanitaria y económica; SEBRAE.

\section{Introdução}

Nos últimos anos o mundo tem presenciado grandes avanços econômicos e tecnológicos nunca antes visto na história da humanidade. Contudo, assim como a facilidade de transporte e diminuição das fronteiras geográficas, a nova conjuntura traz consigo o risco de transmissão de doenças altamente contagiosas, como no caso do COVID-19. Nesse sentido, especialista colocam que o setor de serviços será o mais afetado com a pandemia devido as ações dos governos com a perca de milhões de empregos e reconfiguração do trabalho nas organizações.

Diante da conjuntura atual e dada as peculiaridades do setor de serviços, questiona-se: qual os impactos causados pela pandemia do novo coronavírus no setor de serviços brasileiro nos meses iniciais da crise sanitária e econômica mundial? O objetivo deste estudo é analisar os impactos provocados pela pandemia do novo coronavírus no setor de serviços no país a partir das Pesquisas Anuais de Serviços e Pesquisa Mensal de Serviços do Instituto Brasileiro de Geografia e Estatística (IBGE).

Quanto aos aspectos metodológicos, caracteriza-se como exploratório e descritivo. É exploratória porque busca analisar o contexto econômico do setor de serviços nos primeiros meses de 2020, mais especificamente os meses de março, abril e maio, em que foram adotadas medidas de isolamento social. Da mesma forma, é considerada descritiva ao tentar descrever tais fenômenos e suas implicações a curto e médio prazos para a economia brasileira.

Os resultados mostram que nos primeiros meses de 2020 houve retração no volume de serviços em todas as classificações adotadas pelo IBGE com destaque negativo acentuado as atividades turísticas e correlatas. O recuo em maio de $19,5 \%$ foi o maior já registrado. A recessão acumulada no ano já soma -7,6\% e 2,7\% nos últimos dozes meses. Diante da flexibilização das medidas adotadas pelas autoridades algumas atividades já apresentam sinais de recuperação em 27,7\% dos 166 tipos de serviços analisados como outros serviços, transportes, auxiliares de transportes e correios.

Este estudo mostra-se relevante ao analisar a conjuntura atual no cenário de crise sanitária e econômica, buscando subsidiar medidas de apoio para empresas do setor de serviços de modo a minimizar os efeitos malquistos durante e pós pandemia. Não obstante, a realidade apresenta uma série de dificuldades e oportunidades de pesquisa, como por exemplo, o número reduzido de estudos empíricos e literatura especializada escassa, bem como a carência de dados atualizados sobre as atividades de serviços no Brasil. 


\section{Impactos da Pandemia do Novo Coronavírus na Economia}

Nos últimos anos o mundo tem presenciado grandes avanços econômicos e tecnológicos nunca antes visto na história da humanidade: a abertura das economias; a socialização de e entre culturas e realidades distintas; acesso à internet e tecnologias da comunicação são apenas algumas das inúmeras vantagens conquistadas nas últimas décadas em todo o globo. Contudo, assim como a facilidade de transporte e diminuição das fronteiras, a conjuntura atual traz o risco de transmissão de doenças altamente contagiosas, como no caso do COVID-19 (Aveni, 2020).

Em meados de novembro e dezembro de 2019, a Síndrome Respiratória Aguda Grave 2 (SARS-CoV-2), também conhecida como “coronavírus" e/ou simplesmente “COVID-19” teve seu primeiro caso registrado em humanos na China (GirónPérez, Barrón-Arreola \& Rojas-Mayorquín, 2020; Porsse et al., 2020) De acordo com as autoridades chinesas, em primeiro de janeiro de 2020, haviam 381 pessoas infectadas no país. E no dia onze de março, as autoridades informaram o número de 126.214 infectados no território chinês (Gama Neto, 2020).

Consoante com o Ministério da Saúde [MS] (2020a) os casos registrados apontam complicações como doenças respiratórias, hepáticas, entéricas e neurológicas (Rezende, Marcelino \& Miyaji 2020a). Dada sua forma de contagio, velocidade de propagação e falta de meios para combater seu alastramento e efeitos danosos, a Organização Mundial da Saúde (OMS), declarou, em 11 de março de 2020, o COVID-19 como pandemia (Gama Neto, 2020; Porsse et al., 2020; Rossoni, 2020).

Ainda segundo o MS (2020a) o primeiro caso confirmado no Brasil ocorreu em 26 de fevereiro no estado de São Paulo. Conforme o portal G1.globo.com (2020a) no dia 19 de junho o país registrou mais de um milhão de pessoas infectadas. Apenas 14 dias depois, já eram 1.539.081 pessoas acometidas pelo COVID-19 e em 16 de julho foram 2.014.738 casos confirmados. No período de quatro meses o Brasil atingiu a marca de um milhão de pessoas contaminadas e dobrou esse número em apenas 27 dias (g1.globo.com, 2020b). Conforme MS (2020c) até o dia 16 de julho 76.822 vieram a óbito em decorrência da doença.

Diante deste cenário inóspito e da falta de uma vacina, bem como da morbidade, letalidade e mortalidade da coronavírus em escala global, a OMS juntamente com diversos especialistas da área de saúde de vários países afirma que a principal estratégia para contenção do COVID-19 é o isolamento social (Aveni, 2020; Gama Neto, 2020; Rezende et al., 2020b; Rossoni, 2020).

Atendendo as recomendações das autoridades nacionais e internacionais de saúde, governadores e prefeitos aderiram essas medidas restritivas como o fechamento do comércio e de setores produtivos, redução dos transportes públicos e o distanciamento social (Aveni, 2020; Barría, 2020; Conti, 2020; Gama Neto, 2020). No entanto, se por um lado essas medidas de isolamento social terão êxito em seu proposito inicial, por outro, tais precauções gerou um cenário econômico extremamente conturbado e repleto de incertezas com potencial para ocasionar uma recessão global (Rezende et al., 2020a; Porsse et al., 2020).

Nesse sentido o estudo de Gonzatto et al. (2020) traz as principais consequências das epidemias da humanidade. Em termos de prejuízos estritamente econômicos, a Tabela 1 apresenta o custo em bilhões de dólares das últimas pandemias para as economias globais, bem como um valor aproximado de todas as crises sanitárias desse porte ao longo da história, conforme o editorial do website Otempo.com.br.

Tabela 1. Custo das pandemias do século XXI.

\begin{tabular}{lcc}
\hline Doença & Período & Custo em US\$ \\
\hline Ebola & $2014-2016$ & 53 bilhões \\
H1N1 & $2009-2010$ & 20 bilhões \\
Gripe suína & 2006 & 40 bilhões \\
Síndrome respiratória aguda (Sars) & $2000-2020$ & 40 bilhões \\
Síndrome respiratória do Oriente Médio (Mers) & $2012-2020$ & 10 bilhões \\
\hline
\end{tabular}

Nota: Fonte: Adaptado de Tempo, O. (2020). Coronavírus já é a epidemia mais cara dos últimos 20 anos, diz estudo. Impacto. Recuperado de: https://www.otempo.com.br/mundo/coronavirus-ja-eaepidemia-mais-cara-dos-ultimos-20-anos-diz-estudo-1.2293046. 
Como pode ser observado na Tabela 1, os gastos com as principais pandemias do século XXI, correspondem aproximadamente 163 bilhões de dólares. Ainda de acordo com o site "o tempo", só nos primeiros meses a COVID-19 já havia causado um impacto econômico estimado de 62 bilhões somente à China, sendo considerada a maior cara da história. $\mathrm{O}$ texto traz dados do Banco Mundial em que afirma que o dispêndio de todas as pandemias graves já registradas soma a impressionante cifra de três trilhões de dólares ao longo da história (Tempo, 2020).

Para autores como Girón-Pérez et al. (2020), Rezende et al. (2020a) e Rossoni (2020) o setor de serviços será o mais afetado com a pandemia devido as ações dos governos com a perca de milhões de empregos e reconfiguração do trabalho nas organizações. Dentre os setores mais afetadas nos primeiros meses de pandemia estão distribuição de alimentos e bebidas, salões de beleza, academias, clínicas dos diversos segmentos e, principalmente, os serviços voltados para o turismo (Girón-Pérez et al., 2020; Rossoni, 2020). Corroborando com os autores, Gama Neto (2020) coloca que o primeiro segmento a sentir os efeitos do COVID-19 foi a aviação civil.

Diante desse cenário inóspito a Organização Mundial do Comércio (2020) prever que o comércio internacional terá redução entre 13 a 32\% para este ano. Em março, a Organização para Cooperação e Desenvolvimento Econômico (OCDE, 2020) divulgou um relatório no qual os resultados apontam para uma recessão do setor de serviços. As estimativas são de que o setor de serviços tenha queda entre 50\% a 100\% em diversos países, impactando cerca de 15 a 30\% sobre o Produto Interno Bruto dos países (OCDE, 2020).

Em seu trabalho Porsse et al. (2020) buscaram projetar os impactos da COVID-19 na economia brasileira a partir de dois cenários possíveis. Em ambas projeções, de acordo com os autores, embora alguns setores continuem operando via home office durante o período de restrição a aglomerações de pessoas, o setor de serviços vai ter sua força de trabalho diminuída em $50 \%$ na maioria das atividades e, em alguns casos, essa queda será de 100\% como shoppings, atividades artísticas e culturais, entre outras (Porsse et al., 2020). Outros autores como Carlsson-Szlezak, Reeves e Swartz (2020) e Lazzarini e Musacchio (2020) também buscaram fazer estimativas acerca dos impactos da pandemia na economia. Os resultados são similares aos encontrados por Porsse et al. (2020), principalmente no que se refere a intervenção do Estado com medidas de apoio financeiro.

\section{A Importância do Setor de Serviços para Economia Brasileira}

Em 2005, o Instituto de Pesquisa Econômica Aplicada (IPEA) coordenou o projeto "Estrutura e Dinâmica do Setor de Serviços no Brasil" com vários especialistas que resultou no levantamento da situação do setor de serviços no Brasil. O principal objetivo dessa pesquisa foi levantar informações acerca das empresas do ramo (Silva, Negri \& Kubota, 2006) e representou um marco para as pesquisas no setor ao mostrar as principais características e gargalhos para maior crescimento e produtividade, bem como os principais clusters de serviços no país.

Na literatura é consenso para os vários estudiosos que o setor de serviços é o mais heterogêneo da economia. Essa visão é corroborada por Corrêa e Gianesi (2019), Kon (2004), Pereira (2014) e Silva et al. (2006) que asseveram que este setor apresenta atividades mais dinâmicas que o comércio e a indústria. Nesse sentido, segundo Meirelles (2006, p. 350), "trata-se de um setor que contempla uma gama variada de atividades econômicas, de diferentes características de produto e/ou processo, bem como de organização de mercado".

Consoante com Moraes (2017) somente a partir de 1930 o setor de serviços tornou-se objeto de estudo da economia. Ainda segundo a autora Fisher foi o primeiro autor a distinguir as atividades econômicas em setores sendo a agricultura setor primário; a indústria setor secundário; e o setor terciário formado por atividades distintas dos outros dois setores. Segundo Galinari e Teixeira Junior (2014) e Silva, Menezes Filho e Komatsu (2016), foi na década de 1970 que o setor de serviços ganhou destaque nos estudos econômicos com a desaceleração da indústria. 
Nesse sentido, para classificação do setor, diversos países utilizam uma versão local do modelo estatístico Standard Industrial Classification of All Economic Activities, desenvolvido por especialistas da Organização das Nações Unidas (ONU). De acordo com esse modelo os serviços são classificados em distributivos, às empresas, ao consumidor e sem fins lucrativos (Galinari \& Teixeira Junior, 2014; Kon, 2004).

No Brasil, o Ipea e o Instituto Brasileiro de Geografia e Estatística (IBGE) utilizam em seus trabalhos a Classificação Nacional da Atividade Econômica (Moraes, 2017). O IBGE faz o levantamento dos dados de empresas do setor de serviços nos 27 estados da federação, "com 20 ou mais pessoas ocupadas, que desempenham como principal atividade um serviço não financeiro, excluídas as áreas de saúde e educação" (IBGE, 2020b). Contudo, Moraes (2014), Silva et al. (2006) e Silva et al. (2016) colocam que são excluídas nessa classificação os setores de distribuição de energia elétrica, gás e água, pesquisa e desenvolvimento, atividades associativas e governo.

Consoante com Seleme (2016) e Corrêa e Gianesi (2019), em geral, na literatura contemporânea acerca dessa temática existe um consenso quanto a algumas características intrínsecas aos serviços: intangibilidade, simultaneidade, inestocabilidade e interatividade. De acordo com Meirelles (2006) só pode ser considerada uma modalidade de serviço, "a atividade cujo processo de produção é intangível, baseada em insumos e em ativos intangíveis, cuja relação de produção e consumo é simultânea e interativa, resultando num produto também intangível e inestocável” (p. 351). Para Deluca, Gonçalo, Castro Júnior e Pereira (2017) os serviços se diferenciam de produtos sob três aspectos básicos: pessoas, processos e ambiente.

Nessa perspectiva, o produto resultante do serviço prestado pode ser tanto de natureza tangível quanto intangível, visto que essa atividade pode gerar um ou vários bens físicos, assim como tem a capacidade de gerar informações para o usuário. Todavia, dado seus atributos, a prestação do serviço exige colaboração e assimetria entre prestadores e consumidores (Bareto, Nóbrega \& Souza, 2017; Galinari \& Teixeira Junior, 2014; Meirelles, 2006; Moraes, 2017).

Essa relação é justamente o epicentro da dinâmica competitiva e estrutural de mercado das atividades de serviços, especialmente sob a ótica da estratégia (Bareto et al., 2017). Nesse sentido, as especificidades do setor de serviços podem explicar, até certo ponto, tanto as barreiras de mercado como as disparidades de produtividade das empresas (Corrêa \& Gianesi, 2019; Silva, Aguilar, Ferreira, Oliveira \& Godinho, 2016; Pacheco, Klein \& Reghi, 2016).

De acordo com Kon (2004), Meirelles (2003; 2006) e Silva (2006) e Seleme (2016) a literatura trata os serviços como atividades relacionadas apenas com o trabalho humano, no entanto, fica evidente nos últimos anos que está visão não condiz com a realidade haja vista que os serviços podem ser entendidos como produto simplesmente (visão tradicional), bem como um produto intangível baseado em habilidades pessoais e/ou em informações e conhecimento, sendo considerados serviços modernos ou contemporâneos.

Para Corrêa e Gianesi (2019) esse nicho da economia deve ser analisado sob quatro perspectivas: os serviços como setor ou como atividade; os serviços como diferencial competitivo em empresas de manufaturas; os serviços como centros de lucro em empresas de manufatura; e os serviços como atividades internas de apoio em uma empresa.

Nesse sentido, Silva et al. (2006) salientam que entre 1998 e 2002, a prestação de serviços às empresas baseados em conhecimento obtiveram crescimento muito superiores aos demais serviços, bem como as atividades destinadas as indústrias e ao comercio em relação a fatores econômicos como número de empresas, receita liquida, empregos e média nos salários. Os dados apresentados pelo IBGE (2020b) corroboram com os autores ao constatar que o setor de serviços tem participação de mais de dois terços no Produto Interno Bruto (PIB) atualmente.

Cabe ressaltar que compreender toda a conjuntura por traz desse crescimento do setor de serviços nos últimos anos em termos globais, é resultado cada vez mais acentuado do uso e desenvolvimento de tecnologias capazes de substituir o trabalho manual de centenas de trabalhadores por um pequeno número de máquinas e equipamentos com o mesmo nível de produtividade 
ou ainda maior, principalmente na agropecuária. Essa substituição requer, impreterivelmente, o aporte de serviços de infraestrutura e apoio logístico e tecnológico.

Embora haja um crescimento exponencial da participação tanto no PIB, quanto na geração de empregos, a economia de um país não deve ser voltada majoritariamente para o setor de serviços dada sua baixa heterogeneidade, baixa produtividade e vulnerabilidade ao mercado internacional (Corrêa \& Gianesi, 2019). Nesse sentido, Meirelles (2006) ressalta que a expansão do setor em vários países em desenvolvimento é fortemente condicionada pelo próprio desenvolvimento econômico, pela cultura regional/nacional e pela legislação.

Quanto ao desenvolvimento socioeconômico cabe destacar a especialização dos serviços e, por conseguinte, da mão de obra que será contratada, assim como sua disponibilidade; infraestrutura adequada e disponibilidade logístico com baixos custos de produção e transportes; nível de informatização e tecnológico para atividades especificas; e demanda local e/ou regional (Kon, 2004; 2006; Silva et al., 2016). Segundo Domingues, Ruiz, Moro e Lemos (2006) acrescentam que além dos fatores elencados acima, deve-se considerar também atividades de marketing e propaganda, criação de novos produtos e serviços e mercados consumidores; bem como a terceirização dos serviços em indústrias e outras empresas de serviços.

Com relação a cultura e regionalização das empresas, o estudo de Domingues et al. (2006) utilizando os dados da PAS/SEBRAE mostrou que no Brasil existem 11 macrorregiões econômicas, das quais a região sudeste se destaca com empresas com maior valor agregado. Dentre as cidades pesquisadas apenas a cidade de São Paulo contempla a atuação de empresas nas 93 classificações de serviços utilizadas no trabalho, seguida por Rio de Janeiro (91). Ainda de acordo com os autores, essa é uma peculiaridade do setor no país em que há uma densa concentração espacial associada diversificação setorial nas regiões metropolitanas das capitais.

Cabe destacar ainda, que a amostra do trabalho de Domingues et al. (2006) foram 139 municípios, dos quais 74 destes estão localizados em regiões metropolitanas e o restante (65) estão distribuídos pelo interior dos estados e Distrito Federal. Somados, os 74 municípios, representam cerca de $90 \%$ da massa salarial e $86 \%$ dos trabalhadores empregados no setor. Este estudo mostrou a concentração das empresas de serviços em regiões metropolitanas e capitais brasileiras. Todavia, não são as instalações industriais que sustentam e promovem as empresas de serviços, mas a multiplicidade das atividades inerentes do setor que as fortalecem (Domingues et al., 2006; Moraes, 2017).

Isso demonstra como o setor de serviços é capaz de promover o desenvolvimento socioeconômico local/regional a partir da distribuição territorial das empresas, ou seja, a grande quantidade de empresas situadas na mesma macrorregião é indutora de geração de milhares de empregos dada a heterogeneidade e complexidade do setor (Moraes, 2014; Galinari \& Teixeira Júnior, 2017). Por outro lado, a concentração dessas organizações em regiões geograficamente estratégicas permite que novas indústrias e comércio se instalem nas proximidades demandando serviços de baixa, média e alta complexidade voltados exclusivamente para essa demanda especializada promovendo inovação nos vários segmentos da economia (Domingues et al., 2006; Kon, 2004; Moraes, 2017; Seleme, 2016).

Por fim, fatores ligados a legislação pode-se destacar dois especificamente: o primeiro relacionado as normas trabalhistas que dificultam a contratação formal de trabalhadores dada a burocracia e equidistância da realidade brasileira; o segundo ponto está relacionado com os aspectos fiscais extensamente mencionados na literatura como o maior entrave para o crescimento econômico no Brasil, dada as altas cargas tributarias nas três esferas (federal, estadual e municipal) e o baixo retorno aos contribuintes.

Convém ressaltar que em março de 2017, o então presidente Michel Temer sancionou a lei $n^{\circ}$ 13.429/2017 que ficou conhecida como a nova lei da terceirização (Correia, 2018; Santos, 2017). Para Valente (2020), essa nova regulamentação trouxe maior flexibilização as leis trabalhistas e possibilitou modernizar a legislação trabalhista brasileira sob a égide de que com leis mais flexíveis, as empresas podem contratar mais funcionários gerando emprego e renda e, consequentemente, impulsionar o 
desenvolvimento como ocorre nos países mais avançados. De acordo com Correia (2018) ainda no ano de 2017 foi promulgada a reforma trabalhista (Lei n ${ }^{\circ}$ 13.467/2017) com vista a diminuir a burocracia para contração de pessoal em qualquer atividade da empresa contratante.

Face o cenário de crise sanitária e econômica o governo federal editou várias medidas com vista a estimular a economia e evitar o colapso das empresas. Dentre as ações estão abertura de linhas de crédito emergencial, pausa no pagamento de financiamentos, prorrogação de impostos federais, suspensão de cobranças da dívida ativa da união e maior facilidade de negociação destas, prorrogação do prazo de entrega de documentos obrigatórios a Receita Federal, dispensa de documentos obrigatórios na contratação de empréstimos e financiamentos e criação de um canal de comunicação direta com empresas (uol.com.br, 2020).

Contudo, as maiores ações implementadas pelo governo para enfretamento da crise foram as medidas relacionadas a manutenção dos empregos. Dentre os principais atos para flexibilização das normas trabalhistas estão a suspensão do contrato de trabalho, redução da jornada de trabalho e salários, regularização do teletrabalho (home office), antecipação de férias individuais e concessão de férias coletivas sem aviso prévio, permissão para negociação entre patrão e empregado e prorrogação do recolhimento do FGTS (uol.com.br, 2020).

Todavia, dada toda a conjuntura provocada pela crise sanitária e econômica da coronavírus faz-se necessário criar mecanismos que auxiliem as empresas a se manterem competitivas no mercado não apenas nesse cenário de crise global, mas também a médio e longo prazos. Tais medidas políticas e econômicas vão muito além da reformulação da legislação trabalhista e auxílio financeiro emergencial por parte do governo (Carlsson-Szlezak et al., 2020; Lazzarini \& Musacchio, 2020).

\section{Aspectos Metodológicos}

Até o momento da escrita deste trabalho não há expectativa de que dados sobre os impactos econômicos da pandemia causada pelo COVID-19 estarão disponíveis e acessíveis para reagir à crise provocada pelo novo coronavírus com eficiência. Diante deste cenário de calamidade, faz-se necessário fontes de dados confiáveis para avaliar os prejuízos e planejar as ações que minimizem os efeitos malquistos durante e pós pandemia (Conti, 2020).

Nessa perspectiva, o presente estudo caracteriza-se como uma pesquisa exploratória e descritiva (Vergara, 2007). É exploratória porque busca analisar o contexto econômico do setor de serviços nos primeiros meses de 2020, mais especificamente os meses de março, abril e maio, em que foram adotadas medidas de prevenção ao contagio das pelo COVID-19. Da mesma forma, é considerada descritiva ao tentar descrever tais fenômenos socioeconômicos e suas implicações a curto e médio prazos para a economia brasileira. A principal fonte de pesquisa o repositório do Instituto Brasileiro de Geografia e Estatística (IBGE) disponível em seu website.

Nesse sentido, a abordagem da pesquisa é quantitativa (Pereira et al., 2018; Yin, 2015). O banco de dados utilizado neste trabalho é composto pelas Pesquisas Anuais de Serviços (PAS), as Pesquisas Anuais do Comércio (PAC) e as Pesquisas Industriais Anuais (PIA) referentes aos anos de 2008 e 2017, bem como a Pesquisa Mensal de Serviços (PMS) do mês de maio de 2020 divulgas pelo IBGE. De acordo com Silva et al. (2006) estes documentos constituem fonte de dados imprescindível para as pesquisas relacionadas ao setor de serviços no país.

Nesse sentido, cabe enfatizar que tanto a Pesquisa Anual de Serviços quanto a Pesquisa Mensal de Serviços apresentam informações econômicas-financeiras, bens e serviços consumidos, de produção e demais atividades especificas do setor de serviços referentes as seguintes operações: (i) transporte, armazenagem e correio; (ii) serviços prestados às famílias; (iii) informação e comunicação; (iv) atividades profissionais, científicas e técnicas; (v) atividades administrativas e serviços complementares; (v) outras atividades de serviços (IBGE, 2020b). 
O universo da PAS e da PMS é constituído por empresas de serviços com 20 ou mais funcionários; ter o Cadastro Central de Empresas do IBGE ativo, assim como o Cadastro Nacional da Pessoa Jurídica (CNPJ); ter sua sede em uma das 27 entidades federativas; e ser registrada em um dos cinco agrupamentos de atividades da Classificação Nacional da Atividade Econômica (CNAE) 2.0 (IBGE, 2020c). Cabe ressaltar que para as series temporais os dados recebem o ajuste de sazonalidade que consiste no método estatístico com objetivo de minimizar os efeitos sazonais incidentes (IBGE, 2010b; 2018; 2019b; 2020c).

\section{Resultados e Discussão}

De acordo com SEBRAE (2020b) o setor de serviços respondeu por 74\% do PIB do país em 2019. Ao analisar os dados da Pesquisa Anual de Comércio (PAC), da Pesquisa Anual de Serviços (PAS) e da Pesquisa Industrial Anual (PIA) no intervalo entre 2008 e 2017, nota-se a importância do setor de serviços para economia brasileira quanto a criação de novas empresas e geração de empregos com carteira assinada, conforme apresentado na Tabela 2.

Tabela 2. Número de empresas, pessoal ocupado, salários e retiradas e receita líquida na indústria, comércio e serviços (2008 e 2017).

\begin{tabular}{|c|c|c|c|}
\hline Setor & 2008 & 2017 & Crescimento \% \\
\hline \multicolumn{4}{|c|}{$\mathrm{N}^{\mathrm{o}}$ de empresas } \\
\hline Comércio & $1,4 \mathrm{mi}$ & $1,5 \mathrm{mi}$ & 7,14 \\
\hline Indústria & 475 mil & 318,3 mil & $-32,99$ \\
\hline Serviços & $880 \mathrm{mil}$ & $1,3 \mathrm{mi}$ & 47,73 \\
\hline \multicolumn{4}{|c|}{ Receita operacional liquida (R\$) } \\
\hline Comércio & 1,5 tri & 3,4 tri & 126,67 \\
\hline Indústria & 3,5 tri & 3,0 tri & $-14,28$ \\
\hline Serviços & $680,1 \mathrm{mi}$ & 1,5 tri & 120,55 \\
\hline \multicolumn{4}{|c|}{ Valor adicionado $(\mathrm{R} \$)$} \\
\hline Comércio & $225,8 \mathrm{mi}$ & 583,7 bi & 258.403 \\
\hline Indústria & $1,44 \mathrm{bi}^{\mathrm{a}}$ & $1,2 \operatorname{tri}^{\mathrm{a}}$ & $83.233,34$ \\
\hline Serviços & $376,5 \mathrm{mi}$ & $906,5 \mathrm{mi}$ & 140,77 \\
\hline \multicolumn{4}{|c|}{ Pessoal ocupado } \\
\hline Comércio & $8,2 \mathrm{mi}$ & $10,2 \mathrm{mi}$ & 24,39 \\
\hline Indústria & $15,3 \mathrm{mi}$ & $7,7 \mathrm{mi}$ & $-49,67$ \\
\hline Serviços & $9,2 \mathrm{mi}$ & $12,3 \mathrm{mi}$ & 140,77 \\
\hline \multicolumn{4}{|c|}{ Salários e retiradas $(\mathrm{R} \$)$} \\
\hline Comércio & 83,1 bi & $226,7 \mathrm{bi}$ & 172,8 \\
\hline Indústria & $448,2 \mathrm{mi}$ & 300,4 bi & $66.923,65$ \\
\hline Serviços & $128,1 \mathrm{bi}$ & 336,7 bi & 162,84 \\
\hline \multicolumn{4}{|c|}{ Salário mensal médio (em salários mínimos) } \\
\hline Comércio & 3,0 & 1,8 & $-40,0$ \\
\hline Indústria & 2,5 & 3,2 & 28,0 \\
\hline Serviços & 2,6 & 2,2 & $-15,38$ \\
\hline
\end{tabular}

a É uma aproximação para "valor adicionado da indústria".

Fonte: Instituto Brasileiro de Geografia e Estatística (2010a). Pesquisa anual do comércio 2008. (Vol. 20). Rio de Janeiro: IBGE.

Instituto Brasileiro de Geografia e Estatística (2010b). Pesquisa anual de serviços 2008. (Vol. 10). Rio de Janeiro: IBGE.

Instituto Brasileiro de Geografia e Estatística (2010c). Pesquisa Industrial 2008. (Vol. 27, número 1). Rio de Janeiro: IBGE.

Instituto Brasileiro de Geografia e Estatística (2018). Pesquisa anual do comércio 2017. (Vol. 29). Rio de Janeiro: IBGE.

Instituto Brasileiro de Geografia e Estatística (2019a). Pesquisa anual de serviços 2017. (Vol. 17). Rio de Janeiro: IBGE.

Instituto Brasileiro de Geografia e Estatística (2019b). Pesquisa Industrial 2017. (Vol. 36, número 1). Rio de Janeiro: IBGE

Cabe destacar que dentro do período analisado consoante com a Tabela 2, o setor de serviços teve crescimento superior ao da indústria e do comércio quanto ao número de novas empresas e ao pessoal ocupado. O crescimento receita operacional 
liquida também foi maior que à indústria, embora corresponda apenas a metade do valor, e um pouco menor que a registrada no setor do comércio. Já no que se refere ao valor adicionado os serviços estão muito atrás dos demais setores da economia, com destaque para o setor industrial que cresce a passos largos nesse quesito. Em relação as remunerações, o setor de serviço estão tecnicamente lado a lado com o comércio e muito inferior à indústria. Isso pode ser explicado pela diminuição nos postos de trabalho da indústria e o aumento na renda média mensal ao longo dos anos, uma vez que a indústria foi o único setor que aumentou a remuneração e reduziu o pessoal no período analisado enquanto que o comercio (-40\%) e os serviços $(-15,38 \%)$ tiveram redução de salários e empregou mais pessoas no mesmo período.

A Pesquisa Anual de Serviços mostrou que em 2017 os serviços profissionais, administrativos e complementares constituíam 424.847 empresas e 4,9 milhões postos de trabalho ocupando o primeiro lugar em nível de importância. Seguido por serviços prestados às famílias com 378.957 empresas e 2,77 milhões de empregos, ficou em segundo lugar e, em terceiro colocado, os serviços de transportes, serviços auxiliares aos transportes e correios com 188.508 empresas e 2,5 milhões de trabalhadores (SEBRAE, 2019a). Esse resultado corrobora com os achados de Silva et al. (2006) em que os serviços baseados em conhecimento mantiveram crescimento.

De acordo com SEBRAE (2019a) as atividades que alavancaram as receitas operacionais liquidas do setor em 2017 foram transportes, serviços auxiliares aos transportes e correios ( $\mathrm{R} \$ 449.533 .765,00)$, serviços profissionais, administrativos e complementares ( $R$ \$ 399.949.749,00), serviços de informação e comunicação ( $R$ \$ 343.518.171,00) e serviços prestados às famílias ( $\mathrm{R} \$ 183.484 .018,00)$. As demais atividades tiveram receitas liquidas inferiores a 100 mil reais. Uma possível explicação para essa constatação é que o modal de transportes de escoação da produção no Brasil é ancorado em transportes terrestres.

Quanto aos salários, retiradas e outras remunerações, os serviços profissionais, administrativos e complementares com R \$ 119.101.909,00, foram os únicos a ultrapassar a cifra dos 100 mil reais, seguidos pelos serviços de transportes, auxiliares aos transportes e correios ( $\mathrm{R}$ \$ 83.014.606,00), serviços de informação e comunicação ( $\mathrm{R}$ \$ 55.690.952,00) e serviços prestados às famílias ( $\mathrm{R}$ \$ 49.372.092,00). Cabe frisar que a PAS não investiga empresas do setor de serviços financeiros. Contudo os achados reforçam o estudo de Silva et al. (2006).

Nessa perspectiva, outra forma utilizada pelo SEBRAE para investigação e publicação de dados sobre a economia brasileira, mas especificamente do setor de serviços, é a Pesquisa Mensal de Serviços (PMS). No entanto, a PMS não apresenta informações detalhadas como a PAS, mas serve para monitorar oscilações nos parâmetros pesquisados. A última PAS publicada, considerando o período em que este trabalho estava sendo escrito, foi referente ao mês de maio de 2020. De acordo com esta publicação, o setor de serviços em maio teve retração no volume de atividades de $0,9 \%$ em relação ao mês anterior, sendo a quarta queda consecutiva e acumulando perdas de 7,6\% no ano, conforme Tabela 3.

Tabela 3. Indicadores da Pesquisa Mensal de Serviços Brasil - Maio de 2020.

\begin{tabular}{lcc}
\hline \multicolumn{1}{c}{ Período } & \multicolumn{2}{c}{ Variação (\%) } \\
\cline { 2 - 3 } & Volume & Receita Nominal \\
\hline Maio 20 / Abril 20* & $-0,9$ & $-0,7$ \\
Maio 20 / Maio 19 & $-19,5$ & $-18,8$ \\
Acumulado Janeiro-Maio & $-7,6$ & $-6,0$ \\
Acumulado nos Últimos 12 Meses & $-2,7$ & $-0,1$ \\
\hline * Série com ajuste sazonal & & \\
Fonte: adaptado de Instituto Brasileiro de Geografia e Estatística (2020c). Pesquisa mensal de \\
$\begin{array}{l}\text { serviços maio de 2020. Recuperado de https://biblioteca.ibge.gov.br/index.php/biblioteca- } \\
\text { catalogo?view=detalhes\&id=72419 }\end{array}$
\end{tabular}


A Tabela 3 apresenta um recuo de 19,5\% do setor de serviços se comparado ao mesmo período do ano passado (maio/2019). Outra informação importante é a redução das receitas nominais em todos os comparativos apresentados na tabela, com destaque para as perdas de 6\% nos primeiros cinco meses do ano e de 18,8\% comparado com mesmo período do ano anterior. As atividades que sofreram quedas foram outros serviços $(4,6 \%)$, profissionais, administrativos e complementares ($3,6 \%)$ e serviços de informação e comunicação $(-2,5 \%)$. Contudo, os serviços prestados às famílias assinalaram aumento significativo das atividades (14,9\%), assim como os serviços de transportes, auxiliares aos transportes e correio (4,6\%). Isso pode ser justificado pela flexibilização das medidas de enfretamento ao coronavírus no mês em alguns segmentos. A Tabela 4 descreve com maiores detalhes as variações no volume de serviços. 
Tabela 4. Indicadores do Volume de Serviços, segundo as atividades de divulgação em maio 2020 - Variação (\%).

\begin{tabular}{|c|c|c|c|c|c|c|c|c|c|c|c|c|}
\hline \multirow[b]{2}{*}{ Atividades de Divulgação } & \multicolumn{3}{|c|}{ Mês/Mês anterior (a) } & \multicolumn{3}{|c|}{ Mensal (b) } & \multicolumn{3}{|c|}{ Acumulado no ano (c) } & \multicolumn{3}{|c|}{ Últimos 12 meses (d) } \\
\hline & MAR & ABR & MAI & MAR & ABR & MAI & $\begin{array}{l}\text { JAN- } \\
\text { MAR }\end{array}$ & $\begin{array}{l}\text { JAN- } \\
\text { ABR }\end{array}$ & $\begin{array}{l}\text { JAN- } \\
\text { MAI }\end{array}$ & $\begin{array}{c}\text { Até } \\
\text { MAR }\end{array}$ & $\begin{array}{c}\text { Até } \\
\text { ABR }\end{array}$ & $\begin{array}{c}\text { Até } \\
\text { MAI }\end{array}$ \\
\hline Volume de Serviços - Brasil & $-6,9$ & $-11,9$ & $-0,9$ & $-2,8$ & $-17,3$ & $-19,5$ & $-0,2$ & $-4,5$ & $-7,6$ & 0,7 & $-0,6$ & $-2,7$ \\
\hline 1. Serviços prestados às famílias & $-31,6$ & $-45,1$ & 14,9 & $-33,5$ & $-65,3$ & $-61,5$ & $-10,2$ & $-23,6$ & $-31,0$ & $-1,0$ & $-6,6$ & $-12,0$ \\
\hline 1.1 Serviços de alojamento e alimentação & $-33,8$ & $-45,2$ & 4,1 & $-35,9$ & $-68,1$ & $-63,9$ & $-10,7$ & $-24,5$ & $-32,1$ & $-1,1$ & $-6,7$ & $-12,2$ \\
\hline 1.2 Outros serviços prestados às famílias & $-19,8$ & $-33,0$ & 1,3 & $-19,9$ & $-50,6$ & $-49,1$ & $-7,5$ & $-18,6$ & $-24,8$ & $-0,4$ & $-5,7$ & $-10,7$ \\
\hline 2. Serviços de informação e comunicação & $-1,5$ & $-2,8$ & $-2,5$ & $-0,2$ & $-4,7$ & $-9,0$ & 0,5 & $-0,8$ & $-2,5$ & 2,5 & 2,0 & 0,8 \\
\hline 2.1 Serviços de tecnologia da informação e comunicação (TIC) & $-0,2$ & $-1,0$ & $-1,7$ & 0,8 & $-0,7$ & $-5,1$ & 0,9 & 0,5 & $-0,6$ & 2,8 & 2,5 & 1,5 \\
\hline 2.1.1 Telecomunicações & $-2,3$ & 0,0 & $-1,0$ & $-4,0$ & $-3,9$ & $-5,2$ & $-3,4$ & $-3,5$ & $-3,9$ & $-1,8$ & $-2,0$ & $-2,3$ \\
\hline 2.1.2 Serviços de tecnologia da informação & 2,0 & $-2,3$ & $-2,6$ & 9,8 & 5,7 & $-4,7$ & 9,4 & 8,5 & 5,7 & 11,9 & 11,3 & 9,1 \\
\hline 2.2 Serviços audiovisuais & $-9,1$ & $-22,7$ & $-4,1$ & $-7,9$ & $-32,6$ & $-36,5$ & $-2,6$ & $-10,3$ & $-15,9$ & 1,0 & $-1,3$ & $-4,2$ \\
\hline 3. Serviços profissionais, administrativos e complementares & $-4,3$ & $-10,4$ & $-3,6$ & $-3,7$ & $-17,5$ & $-21,7$ & $-2,4$ & $-6,3$ & $-9,6$ & 0,2 & $-1,2$ & $-3,1$ \\
\hline 3.1 Serviços técnico-profissionais & 1,3 & $-4,8$ & $-5,9$ & 3,2 & $-12,3$ & $-15,4$ & $-0,9$ & $-4,0$ & $-6,4$ & 2,9 & 1,6 & 0,5 \\
\hline 3.2 Serviços administrativos e complementares & $-7,4$ & $-10,6$ & $-1,8$ & $-6,0$ & $-19,4$ & $-23,8$ & $-2,9$ & $-7,1$ & $-10,7$ & $-0,7$ & $-2,1$ & $-4,4$ \\
\hline 4. Transportes, serviços auxiliares aos transportes e correio & $-8,8$ & $-17,8$ & 4,6 & 0,4 & $-21,2$ & $-20,8$ & 1,0 & $-4,6$ & $-8,0$ & $-1,9$ & $-3,2$ & $-5,3$ \\
\hline 4.1 Transporte terrestre & $-10,5$ & $-20,5$ & 6,6 & $-5,7$ & $-28,4$ & $-24,4$ & $-3,3$ & $-9,6$ & $-12,7$ & $-3,4$ & $-5,4$ & $-8,1$ \\
\hline 4.2 Transporte aquaviário & $-0,5$ & $-0,1$ & $-1,7$ & 24,1 & 16,3 & 10,6 & 15,6 & 15,8 & 14,7 & 5,7 & 7,2 & 7,8 \\
\hline 4.3 Transporte aéreo & $-27,1$ & $-73,1$ & 9,2 & $-11,6$ & $-77,1$ & $-76,1$ & 1,6 & $-16,6$ & $-30,4$ & $-5,4$ & $-9,1$ & $-15,5$ \\
\hline 4.4 Armazenagem, serviços auxiliares aos transportes e correio & $-1,0$ & $-6,0$ & 1,9 & 8,3 & $-4,4$ & $-5,4$ & 4,6 & 2,3 & 0,7 & $-0,2$ & $-0,1$ & $-0,8$ \\
\hline 5. Outros serviços & $-1,9$ & $-6,4$ & $-4,6$ & 14,0 & 0,8 & $-7,3$ & 11,0 & 8,4 & 5,2 & 7,8 & 7,8 & 6,4 \\
\hline
\end{tabular}

(a) Base: mês imediatamente anterior - com ajuste sazonal;

(b) Base: igual mês do ano anterior;

(c) Base: igual período do ano anterior

(d) Base: 12 meses anteriores

Fonte: adaptado de Instituto Brasileiro de Geografia e Estatística (2020c). Pesquisa mensal de serviços maio de 2020. Recuperado de https://biblioteca.ibge.gov.br/index.php/bibliotecacatalogo?view=detalhes\&id=72419. 
Conforme pode ser observado na Tabela 4, o mês de maio teve uma taxa decrescente acentuada no volume de serviços (19,5\%) frente a maio de 2019, sendo a maior queda histórica desde 2011, quando teve início a mensuração. Cabe destacar que dos 166 serviços pesquisados, apenas 22,3\% apresentaram crescimento o que resultou na retração de todas as cinco categorias analisadas. Essa recessão no volume de serviços foi impulsionada pelas baixas dos serviços prestados às famílias (-61,5\%), dos serviços profissionais, administrativos e complementares $(-21,7 \%)$ e dos transportes, serviços auxiliares aos transportes e correio (-20,8\%) em decorrência das medidas de isolamento social conforme previsto por Poorse et al. (2020).

Considerando a retração acumulada do ano, a diminuição no volume de serviços foi de 7,6\% no comparativo com os primeiros cinco meses de 2019. Contudo, das cinco atividades pesquisadas, apenas "outros serviços" assinalaram crescimento (5,2\%). Outro dado importante da PMS de maio/2020, é que dos 166 tipos, houve crescimento em 27,7\% dos serviços. O destaque negativo ficou com os serviços prestados as famílias que registrou baixa no volume de serviços de $31 \%$ justificada pela queda no faturamento de hotéis, bufê e restaurantes.

O relatório final traz ainda os resultados regionais com o desempenho de cada estado mais o Distrito Federal. Os resultados mostram que na comparação com abril, 16 estados apresentaram recuo no volume de serviços em maio. Os entes federativos com maiores perdas foram Distrito Federal (-13,9 \%) e São Paulo. Dos estados com crescimento destacam-se Santa Catarina (6,4\%), Rio Grande do Sul (5,2\%) e Bahia (4,7\%). Em relação ao mesmo período do ano anterior, a queda de $19,5 \%$ ocorreu em quase todos os estados, exceto em Rondônia que apresentou crescimento de 4,1\% (SEBRAE, 2020c).

Por fim a PMS de maio de 2020 aponta como principal resultado do período, a retração das atividades turísticas calculadas em $68,1 \%$ desde o início das ações de enfretamento da crise, especialmente no que se refere as medidas de isolamento social no Brasil, que corresponde aos meses de março, abril e maio, conforme previsto por Gama Neto (2020), Girón-Pérez et al., (2020), OCDE (2020) e Rossoni (2020).

Apesar da fiscalização dessas medidas de isolamento social pelas autoridades competentes, os serviços relacionados ao turismo como transportes de passageiros, hotéis e restaurantes apresentaram uma alta de 6,6\% em relação a abril de 2020. Os maiores índices registrados foram de Santa Catarina (25,4\%), Paraná (19,3\%), Rio de Janeiro (15,5\%) e Minas Gerais (13,5\%). Ao comparar o acumulado do ano em relação ao mesmo período de 2019, ficou constatado um recuo de 29,9\% no volume dos serviços, onde todos os estados tiveram taxas negativas, quatro deles superiores a 30\%: Rio Grande do Sul (-35,8\%), São Paulo $(-31,5 \%)$, Minas Gerais $(-30,2 \%)$, e Paraná $(-30,2 \%)$.

\section{Considerações Finais}

Os primeiros meses de 2020 apresentaram retração no volume de serviços em todas as cincos classificações adotadas pelo IBGE com destaque negativo acentuado as atividades turísticas e correlatas. O recuo em maio de 19,5\% foi o maior já registrado e pode ser explicado pela implementação das medidas de isolamento social e fechamento de estabelecimentos empresariais. A recessão acumulada no ano já soma -7,6\% e 2,7\% nos últimos dozes meses. Com base nestes dados é licito supor que as empresas foram beneficiadas com as medidas de proteção e manutenção dos empregos, especialmente no que se refere as férias coletivas, redução da jornada de trabalho e salários, negociação direta com o empregado, entre outras, como forma de reduzir os prejuízos causados pela pandemia do novo coronavírus.

Diante da flexibilização das medidas adotadas pelas autoridades algumas atividades já apresentam sinais de recuperação em 27,7\% dos 166 tipos de serviços analisados como outros serviços, transportes, auxiliares de transportes e correios. Os próximos meses serão cruciais para o controle da contaminação e, consequentemente, o relaxamento das medidas de segurança e retomada econômica com reabertura do comércio e demais setores da economia. 
Os serviços prestados as famílias devem voltar a funcionar e mesmo com as restrições sanitárias de combate ao COVID19 as previsões são de crescimento das atividades, principalmente os restaurantes, estabelecimentos de comida e alojamento que são atividades de apoio aos serviços de transportes rodoviários.

A previsão de retomada de crescimento dos serviços de informação e comunicação também e eminente. A retração do segmento pode ser explicada por suas características de simultaneidade e interatividade com os clientes terem sido comprometidas pelas medidas de distanciamento social e fechamento de empresas comprometendo a demanda por serviços de agências de notícias, audiovisuais, de telecomunicações e de tecnologia da informação.

Por fim, a pandemia trouxe grandes transtornos as organizações sob diversos aspectos e exigiu que as empresas promovessem mudanças drásticas e repentinas das quais não estavam preparadas para agir. As projeções mais otimistas dizem que dificilmente haverá recuperação econômica em escala global antes de uma vacina para o novo coronavírus. Diante destas projeções, os serviços profissionais, administrativos e complementares têm, nesse período de crise, uma grande oportunidade de remodelagem estrutural para atender essa nova demanda.

As empresas ainda não sabem como agir para se manterem no mercado e como se posicionar nesse novo cenário de incertezas e, consequentemente, precisam de suporte técnico especializado nas diversas áreas do conhecimento. Este é um campo fértil para os serviços de consultoria empresarial crescerem em número de empresas, empregos e receita, bem como notoriedade, principalmente junto as micro, pequenas e médias empresas uma vez que estas são apontadas como as que mais irão sentir os impactos da pandemia.

Como limitação de pesquisa está a falta de dados mais atualizados, especialmente no que se refere ao número de empresas, geração de empregos e massa salarial do setor de serviços. Outra limitação do estudo foi em relação aos dados sobre os meses iniciais da pandemia, uma vez que não há informações suficientes acerca dos impactos causados em termos financeiros. Nesse sentido, recomendamos pesquisas futuras com vista a evidenciar com maior riqueza de detalhes os efeitos socioeconômicos decorrentes da crise do COVID-19.

O estudo sugere uma série de direcionamentos paras pesquisas futuras sobre o impacto da pandemia do novo Corona Vírus no setor de serviços da economia brasileira. Como sugestão de pesquisas futuras, sugere-se que sejam realizados novos estudos como outras fontes de dados, assim como outros métodos de análises como forma confrontar os resultados deste estudo. Outra sugestão de pesquisa é comparar os impactos nos estados brasileiros com vista é verificar quais os estados mais afetados com a pandemia. Por fim, sugere-se novas pesquisas em setores de serviços mais específicos como turismo, para evidenciar detalhadamente os impactos da pandemia nestes segmentos da economia.

Ademais, almeja-se que este estudo possa contribuir como fonte de pesquisa para trabalhos futuros do setor de serviços. Em termos práticos, espera-se que este estudo possa servir de referência para o planejamento estratégico das empresas com vistas a superar os efeitos malquistos da pandemia do novo coronavírus e servir de aporte para outros cenários que requerem ações que permitam reconstruir a economia, as organizações e a sociedade.

\section{Referências}

Aveni, A. (2020). Estratégias pelo trabalho no futuro devidos a pandemia COVID-19. Revista Processus de Políticas Públicas e Desenvolvimento Social, 2(3), 4-14.

Bareto, M. C., Nóbrega, K. C., \& Souza, L. A. (2017). Estratégia de serviços: o que há de comum entre os modelos teóricos? Revista Raunp, 9(2), 57-68.

Barría, C. (2020). Coronavírus: o que as grandes economias do mundo estão fazendo para evitar falências e a falta de dinheiro. https://www.bbc.com/portuguese/internacional-51983863

Carlsson-Szlezak, P., Reeves, M., \& Swartz, P. (2020). What Coronavirus Could Mean for the Global Economy. Harvard Business Review, 1-10.

Conti, T. V. (2020). Crise Tripla do COVID-19: um olhar econômico sobre políticas públicas de combate à pandemia. http://thomasvconti.com.br/pubs/coronavirus/ 
Corrêa, H. L., \& Gianesi, I. G. N. (2019). Administração estratégica de serviços: operações para satisfação do cliente. (2a ed.). Atlas.

Correia, H. (2018). Terceirização na atividade-fim: julgamento do STF de 30/8/18. https://www.migalhas.com.br/depeso/286807/terceirizacao-na-atividade-fimjulgamento-do-stf-de-30-8-18

Deluca, M. A. M., Gonçalo, C. R., Castro Junior, D. F. L, \& Pereira, M. F. (2017). Capacidades de Inovação em Serviços: Um Estudo nos Supermercados em Santa Catarina. Revista Ibero-Americana de Estratégia (RIAE), 16(1).

Domingues, E. P., Ruiz, R. M., Moro, S., \& Lemos, M. B. (2006). Organização territorial dos serviços no Brasil: polarização com frágil dispersão. In Negri, J. A., \& Kubota, L. C. (Orgs.). Estrutura e dinâmica do setor de serviços no Brasil (Cap., pp. 193-229). IPEA.

G1.globo.com (2020a). Brasil tem mais de 1 milhão de casos confirmados de coronavírus, aponta consórcio de veículos de imprensa; veja a situação por região. https://g1.globo.com/bemestar/coronavirus/noticia/2020/06/19/brasil-tem-mais-de-1-milhao-de-casos-confirmados-de-coronavirus-aponta-consorcio-deveiculos-de-imprensa-veja-a-situacao-por-regioes.ghtml

G1.globo.com (2020b). Brasil atinge 2 milhões de casos de coronavírus; 9 estados mais DF têm alta de mortes, mostra consórcio de veículos de imprensa. https://g1.globo.com/bemestar/coronavirus/noticia/2020/07/16/casos-e-mortes-por-coronavirus-no-brasil-em-16-de-julho-segundo-consorcio-de-veiculos-deimprensa.ghtml

Galinari, R., Texeira Junior, J. R. (2014). Serviços: conhecimento, inovação e competitividade In Banco Nacional de Desenvolvimento Econômico e Social [BNDES]. BNDES Setorial 39. (Cap. 7, pp. 235-289). Rio de Janeiro: BNDES.

Gama Neto, R. B. (2020). Impactos da COVID-19 sobre a economia mundial. Boletim de Conjuntura (BOCA), 2(5), 113-127. http://doi.org/10.5281/zenodo.3786698

Girón-Pérez, M. I., Barrón-Arreola, K. S., \& Rojas-Mayorquín, A. E. (2020). The COVID-19 pandemic: impact in Health and Economy. Revista Bio Ciencias, 7, e963. https://doi.org/10.15741/revbio.07.e963

Gonzatto, M., Corso, M., Senhoras, E. M., Segata, J., Meneghetti Neto, A., \& Veronese, M. V. (2020). Mudanças de comportamento, na economia e no trabalho: como as epidemias transformam o mundo. GaúchaZH, março/2020.

Instituto Brasileiro de Geografia e Estatística (2010a). Pesquisa anual do comércio 2008. (Vol. 20). IBGE.

Instituto Brasileiro de Geografia e Estatística (2010b). Pesquisa anual de serviços 2008. (Vol. 10). IBGE.

Instituto Brasileiro de Geografia e Estatística (2010c). Pesquisa Industrial 2008. (Vol. 27, número 1). IBGE.

Instituto Brasileiro de Geografia e Estatística (2018). Pesquisa anual do comércio 2017. (Vol. 29). IBGE.

Instituto Brasileiro de Geografia e Estatística (2019a). Pesquisa anual de serviços 2017. (Vol. 17). IBGE.

Instituto Brasileiro de Geografia e Estatística (2019b). Pesquisa Industrial 2017. (Vol. 36, número 1). IBGE

Instituto Brasileiro de Geografia e Estatística (2020a). Desemprego. https://www.ibge.gov.br/explica/desemprego.php

Instituto Brasileiro de Geografia e Estatística (2020b). Serviços. https://www.ibge.gov.br/estatisticas/economicas/servicos.html

Instituto Brasileiro de Geografia e Estatística (2020c). Pesquisa mensal de serviços maio de 2020. https://biblioteca.ibge.gov.br/index.php/bibliotecacatalogo? view $=$ detalhes\&id= 72419

Kon, A. (2004). Economia de serviços: teoria e evolução no Brasil. Elsevier/Campus.

Kon, A. (2006). Características econômicas das indústrias de serviços no Brasil: uma comparação entre empresas de capital estrangeiro e de capital nacional. In Negri, J. A., \& Kubota, L. C. (Orgs.). Estrutura e dinâmica do setor de serviços no Brasil (Cap. 5, pp. 133-191). Brasília: IPEA.

Lazzarini, S. G., \& Musacchio, A. (2020). Leviathan as a Partial Cure? Opportunities and Pitfalls of Using the State-Owned Apparatus to Respond to the COVID19 Crisis. RAUSP Management Journal, http://dx.doi.org/10.1590/0034-76122020120x.

Martins, J. (2020). Pandemia COVID-19. Gazeta Médica, 7(1). https://doi.org/10.29315/gm.v7i1.312

Meirelles, D. S. (2003). O setor de serviços e os serviços de infra-estrutura econômica. Tese de doutorado, Universidade Federal do Rio de Janeiro, Rio de Janeiro, RJ, Brasil.

Meirelles, D. S. (2006). Características das firmas e dos setores de serviço, segundo o processo de trabalho. In Negri, J. A., \& Kubota, L. C. (Orgs.). Estrutura e dinâmica do setor de serviços no Brasil (Cap. 10, pp. 349-375). IPEA.

Mistério da Saúde (2020a). O Brasil confirma primeiro caso da doença. https://www.saude.gov.br/noticias/agencia-saude/46435-brasil-confirma-primeiro-casode-novo-coronavirus

Mistério da Saúde (2020b). Coronavírus: 43.079 casos e 2.741 mortes. https://www.saude.gov.br/noticias/agencia-saude/46764-coronavirus-43-079-casos-e-2741-mortes.

Mistério da Saúde (2020c). Painel Coronavírus. https://covid.saude.gov.br/

Moraes, P. P. (2017). Desconcentração regional do setor de serviços na economia brasileira: uma análise do período 2003/2014. Monografia de graduação, Instituto de Economia, Universidade Federal do Rio de Janeiro, Rio de Janeiro, Brasil. 
Nassif, V. M. J., Armando, E., \& Falce, J. L. L. (2020). O empreendedorismo e a pequena empresa no contexto do pós COVID-19: há luz no fim do túnel? Revista de Empreendedorismo e Gestão de Pequenas Empresas (REGEPE). 9(3), 1-7. https://doi.org/10.14211/regepe.v9i3.1940

Organização Mundial do Comércio (2020). Trade set to plunge as COVID-19 pandemic upends global economy. https://www.wto.org/english/news_e/pres20_e/pr855_e.htm

Organização para Cooperação e Desenvolvimento Econômico (2020). Coronavirus: The world economy at risk. https://www.oecd-ilibrary.org/economics/oecdeconomic-outlook/volume-2019/issue-2_7969896b-en;jsessionid=0sZeMuKbT4XjZT7ebpThnTLf.ip-10-240-5-26

Pacheco, F. B., Klein, A. Z., \& Righi, R. R. (2016). Modelos de negócio para produtos e serviços baseados em internet das coisas: uma revisão da literatura e oportunidades de pesquisas futuras. Revista de Gestão (REGE), 23, 41-51.

Pereira, V. R. (2014). O setor de serviços no Brasil (Dissertação de Mestrado). Universidade Estadual Paulista "Julio de Mesquita Filho", Araracuara, SP, Brasil.

Pereira A. S. et al. (2018). Metodologia da pesquisa científica. UFSM.

Porsse, A. A., Souza, K. B., Carvalho, T. S., \& Vale, V. A. (2020). Impactos econômicos do COVID-19 no Brasil. Nota Técnica NEDUR-UFPR, Nº1-2020, Núcleo de Estudos em Desenvolvimento Urbano e Regional (NEDUR) da Universidade Federal do Paraná.

Rezende, A. A., Marcelino, J. A., \& Miyaji, M. (2020a). A reinvenção das vendas: as estratégias das empresas brasileiras para gerar receitas na pandemia de COVID-19. Boletim de Conjuntura (BOCA), 2(6), 53-69. http://doi.org/10.5281/zenodo.3834095

Rezende, A. A., Marcelino, J. A., \& Miyaji, M. (2020b). Impactos iniciais da COVID-19 nas micro e pequenas empresas do Estado do Paraná - Brasil. Boletim de Conjuntura (BOCA), 2(5), 101-112. http://doi.org/10.5281/zenodo.3779308

Rossoni, L. (2020). COVID-19, Organizações, Trabalho em Casa e Produção Científica. Revista Eletrônica de Ciência Administrativa (RECADM), 19(2), 158168. http://dx.doi.org/10.21529/RECADM.2020ed2.

Santos, E. R. (2018). A nova lei da terceirização - Lei no 13.429/2017 - Um cheque em branco ao empresariado. Revista Fórum Trabalhista (RFT), 25. https://www.editoraforum.com.br/noticias/nova-lei-da-terceirizacao-lei-no-13-4292017-um-cheque-em-branco-ao-empresariado/

Seleme, R. (2016). Gestão de operações de serviços: planejando o sucesso no atendimento ao cliente. InterSaberes.

Silva, A. C. V., Aguilar, J. J., Ferreira, S. C. X., Oliveira, T. C., \& Godinho, L. A. de C. (2016). Estudos das estratégias de prestação de serviços em uma empresa do setor de beleza. Caderno de Administração, 24(1), 66-77.

Silva, A. M. (2006). Dinâmica da produtividade do setor de serviços no Brasil: uma abordagem microeconômica. In Negri, J. A., \& Kubota, L. C. (Orgs.). Estrutura e dinâmica do setor de serviços no Brasil (Cap. 3, pp. 73-106). IPEA.

Silva, A. M., Negri, J. A., \& Kubota, L. C. (2006). Estrutura e dinâmica do setor de serviços no Brasil. In Negri, J. A., \& Kubota, L. C. (Orgs.). Estrutura e dinâmica do setor de serviços no Brasil (Cap. 1, pp. 15-33). IPEA.

Silva, C. M., Menezes Filho, N. A., \& Komatsu, B. K. (2016). Uma abordagem sobre o setor de serviços na economia brasileira. Insper.

Tempo, O. (2020). Coronavírus já é a epidemia mais cara dos últimos 20 anos, diz estudo. Impacto. https://www.otempo.com.br/mundo/coronavirus-ja-eaepidemia-mais-cara-dos-ultimos-20-anos-diz-estudo-1.2293046

United Nations (2020). COVID-19: The global food supply chain is holding up, for now. UN News. https://news.un.org/en/story/2020/04/1061032

Uol.com.br (2020). Coronavírus: veja as medidas econômicas do governo para ajudar empresas. https://economia.uol.com.br/noticias/estadaoconteudo/2020/04/14/medidas-economicas-contra-coronavirus-veja-os-anuncios-voltados-as-empresas.htm?cmpid=copiaecola

Valente, F. (2020). STF declara constitucional lei que permite terceirização de atividades-fim. https://www.conjur.com.br/2020-jun-16/stf-declaraconstitucional-lei-permite-terceirizacao-atividades-fim

Vergara, S. C. (2007). Relatórios de pesquisa em administração. (8 ed.). Atlas.

Yin, R. K. (2015). O estudo de caso. Bookman. 